https://helda.helsinki.fi

Gene expression changes related to immune processes associate with cognitive endophenotypes of schizophrenia

\title{
Ukkola-Vuoti, L.
}

2019-01-10

Ukkola-Vuoti , L , Torniainen-Holm , M , Ortega-Alonso , A , Sinha , V , Tuulio-Henriksson , A , Paunio , T , Lönnqvist , J , Suvisaari , J \& Hennah , W 2019, ' Gene expression changes related to immune processes associate with cognitive endophenotypes of schizophrenia ', Progress in Neuro-Psychopharmacology \& Biological Psychiatry , vol. 88 , pp. 159-167 . https://doi.org/10.1016/j.pnp

http://hdl.handle.net/10138/249029

https://doi.org/10.1016/j.pnpbp.2018.07.003

publishedVersion

Downloaded from Helda, University of Helsinki institutional repository.

This is an electronic reprint of the original article.

This reprint may differ from the original in pagination and typographic detail.

Please cite the original version. 


\title{
Gene expression changes related to immune processes associate with cognitive endophenotypes of schizophrenia
}

\author{
Ukkola-Vuoti L. ${ }^{\mathrm{a}, \mathrm{b}, \mathrm{c}}$, Torniainen-Holm M., ${ }^{\mathrm{a}, \mathrm{b}}$, Ortega-Alonso A. ${ }^{\mathrm{a}, \mathrm{b}}$, Sinha V. ${ }^{\mathrm{a}, \mathrm{b}, \mathrm{c}}$, \\ Tuulio-Henriksson A. ${ }^{\mathrm{d}, \mathrm{e}}$, Paunio T. ${ }^{\mathrm{f}, \mathrm{g}}$, Lönnqvist J., ${ }^{\mathrm{b}}$, Suvisaari J. ${ }^{\mathrm{b}}$, Hennah W. ${ }^{\mathrm{a}, \mathrm{b}, \mathrm{c}, *}$

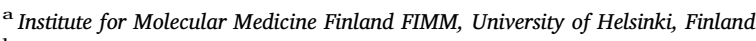 \\ ${ }^{\mathrm{b}}$ Mental Health Unit, Department of Public Health Solutions, National Institute for Health and Welfare, Helsinki, Finland \\ ${ }^{\mathrm{c}}$ Medicum, Faculty of Medicine, University of Helsinki, Helsinki, Finland \\ ${ }^{\mathrm{d}}$ Department of Psychology and Logopedics, Faculty of Medicine, University of Helsinki, Finland \\ e Research at Kela, The Social Insurance Institution Finland, Helsinki, Finland. \\ ${ }^{\mathrm{f}}$ Department of Psychiatry, University of Helsinki and Helsinki University Hospital, Finland \\ ${ }^{\mathrm{g}}$ Genomics and Biomarkers Unit, Department of Public Health Solutions, National Institute for Health and Welfare, Helsinki, Finland
}

\section{A R T I C L E I N F O}

\section{Keywords:}

Schizophrenia

Cognition

Endophenotypes

Gene expression

Immune

\begin{abstract}
A B S T R A C T
Schizophrenia is a heterogeneous disorder characterized by a spectrum of symptoms and many different underlying causes. Thus, instead of using the broad diagnosis, intermediate phenotypes can be used to possibly decrease the underlying complexity of the disorder. Alongside the classical symptoms of delusions and hallucinations, cognitive deficits are a core feature of schizophrenia. To increase our understanding of the biological processes related to these cognitive deficits, we performed a genome-wide gene expression analysis. A battery of 14 neuropsychological tests was administered to 844 individuals from a Finnish familial schizophrenia cohort. We grouped the applied neuropsychological tests into five factors for further analysis. Cognitive endophenotypes, whole blood mRNA, genotype, and medication use data were studied from 47 individuals. Expression level of several RNA probes were significantly associated with cognitive performance. The factor representing Verbal Working Memory was associated with altered expression levels of 11 probes, of which one probe was also associated with a specific sub-measure of this factor (WMS-R Digit span backward). While, the factor Processing speed was related to one probe, which additionally associated among 55 probes with a specific sub-measure of this factor (WAIS-R Digit symbol). Two probes were associated with the measure recognition memory performance. Enrichment analysis of these differentially expressed probes highlighted immunological processes. Our findings are in line with genome-wide genetic discoveries made in schizophrenia, suggesting that immunological processes may be of biological interest for future drug design towards schizophrenia and the cognitive dysfunctions that underlie it.
\end{abstract}

\section{Introduction}

Schizophrenia is a heterogeneous mental disorder characterized by a spectrum of psychological symptoms. In addition to positive and negative symptoms, cognitive deficits are a core feature of the illness (American Psychiatric Association, 1994). Several domains of cognition, including attention (Cornblatt and Erlenmeyer-Kimling, 1985), verbal skills, working memory, learning, and processing speed (McGrath et al., 2014; Dickinson et al., 2004; Nuechterlein et al., 2004) are impaired in individuals with schizophrenia. These impairments can vary from mild to severe between patients, however, within the same patient, cognitive dysfunctions are fairly stable over time. Impairments

\footnotetext{
Abbreviations: CFA, confirmatory factor analysis; CFI, Comparative Fit Index; CVLT, California Learning Test; DISC1, Disrupted In Schizophrenia 1 gene; EIF2, Eukaryotic Initiation Factor-2; FAM89A, Family With Sequence Similarity 89 Member A gene; FDR, false discovery rate; HLA-G, human leukocyte antigen G; HYDIN, Hydrocephalus-Inducing Protein Homolog gene; IPA, Ingenuity Pathway Analysis software; MAF, minor allele frequency; MCH, major histocompatibility complex; MCMC, Monte Carlo Markov chain method in missing data imputation; NDE1, nuclear distribution element 1 gene; Nogo, Neurite outgrowth inhibitor protein encoded by RTN4 gene; PTGER4, prostagladin E receptor gene; RIN, RNA integrity number; RMSEA, Root Mean Square Error of Approximation; RTN4, Reticulon 4 gene; SEM, structural equation modelling; TLI, Trucker Lewis Index; WAIS-R, Wechsler Adult Intelligence Scale—Revised; WMS-R, Wechsler Memory Scale—Revised

* Corresponding author at: Institute for Molecular Medicine, Finland FIMM, P.O. Box 20, FI-00014, University of Helsinki, Finland.

E-mail address: william.hennah@helsinki.fi (W. Hennah).
} 
in cognitive functions are often present already before the hallmark positive symptoms of the illness appear (Cornblatt and ErlenmeyerKimling, 1985). Antipsychotic medications, commonly prescribed to treat schizophrenia, do not provide clinically meaningful improvements on the patients' cognitive domains (Koola et al., 2014). This means that treatment of the cognitive dysfunctions in people with schizophrenia is one of the great unmet clinical challenges (Keefe et al., 2013; Koola et al., 2014).

Intermediate endophenotypes have been proposed to facilitate uncovering the heterogeneous genetic aetiology of schizophrenia. Endophenotypes are invisible but measurable illness-related traits, which are assumed to be closer to a neurobiological aetiology than the disorder itself or its' varying symptoms (Flint and Munafo, 2007; Gottesman and Gould, 2003; Gottesman and Shields, 1973). Key qualities of an endophenotype are heritability, state independency, and the fact that they might be manifested in unaffected relatives of a patient (Gottesman and Gould, 2003). The aforementioned characteristics have been suggested to make endophenotypes ideal alternative measures in the study of the biological aetiology of familial complex traits. Cognitive ability fulfils these characteristics of an endophenotype, it is inherited, and unaffected family members of a patient may show mild deficits (e.g. Braff, 2015). Many cognitive variables, such as, measures of verbal learning, working memory, and attention, have been suggested to function as schizophrenia related endophenotypes (Flint and Munafo, 2007; Tuulio-Henriksson et al., 2003; Tuulio-Henriksson et al., 2002).

Through the application of endophenotypes in genetic analysis, several genetic loci have previously been associated with cognitive functioning in schizophrenia. Family-based studies have linked the chromosome regions 1q (Cannon et al., 2005; Hennah et al., 2005), 2q (Paunio et al., 2004), 4q (Paunio et al., 2004), and 7q22 (Wedenoja et al., 2008; Wedenoja et al., 2010), containing the DISC1, TSNAX, and $R E L N$ genes in Finnish families. Population-based studies have associated the genomic regions nearby or in the genes ATRNL1, KRTAP7-1, C9orf5, CRTC3, MYRIP, DCDC2, FAM110C, DIP2C, KCTD2 (Luciano et al., 2011), CADM2 (Ibrahim-Verbaas et al., 2016), TCF20, CACNA1C, and AKAP6 (Smeland et al., 2017). Here, as in those for schizophrenia, observations from population-based studies are markedly different to those made in familial studies, highlighting the issue of heterogeneity also in this genetic aetiology. To date, genome-wide studies specifically of intelligence, that is often described as combination of many cognitive abilities, have identified a total of 18 independent genomic loci and 22 genes (Sniekers et al., 2017).

In the case of gene expression analysis with endophenotypes, a previous study within Swedish and Finnish twin cohorts studied the genome-wide expression levels of genes, identifying under-expression of genes in relation to memory performance in schizophrenia patients (Zheutlin et al., 2016). The memory related probes associated in this study with diagnostic status and verbal memory as an endophenotype were overlapping with genes that have been previously associated with schizophrenia (SMARCAL1, MCM3, SBK1, ZNF142, ATIC, CBLB, ELP3, ACO1, GTPBP3, YARS, and RUNX3), as well as neurocognition (NCALD) (Zheutlin et al., 2016).

Thus, we set out to investigate if genome-wide gene expression variables can be identified to associate with psychological endophenotypes in familial schizophrenia, and therefore highlight any biological processes that may be disrupted in these traits. In order to increase our understanding of the biological aetiology of cognitive dysfunction in schizophrenia. Such an approach has the potential to further our understanding of the pathophysiology of this devastating disorder, and identify prospective mechanisms through which it may be possible to design future treatments.

\section{Material and methods}

\subsection{Study samples}

The samples used here are part of a larger study project of familial schizophrenia: Genetic Epidemiology and Molecular Genetics of Schizophrenia in Finland. In these projects, individuals born between the years 1940 and 1976 with a diagnosis of schizophrenia, schizoaffective disorder or schizophreniform disorder were identified from three nationwide health care registers: the Finnish Hospital Discharge Register, the Pension Register and the Medication Reimbursement Register (Hennah et al., 2003; Hovatta et al., 1998). Two samples with high familial loading for schizophrenia were collected. The first sample consisted of families with schizophrenia, schizoaffective disorder or schizophreniform disorder collected from a Finnish sub-isolate with an increased relative- risk (Hovatta et al., 1997) for schizophrenia. The other sample was collected from the rest of Finland and consisted of families with at least two siblings with schizophrenia, schizoaffective disorder or schizophreniform disorder. The Diagnostic and Statistical Manual of Mental Disorders, fourth edition, (DSM-IV) (American Psychiatric Association, 1994) diagnoses were made from affected family members by a mental health professional at psychiatric hospitals and outpatient care centres (Arajärvi et al., 2004). Based on these diagnoses two researchers independently made best estimate consensus diagnoses using the DSM-IV criteria (American Psychiatric Association, 1994). If there was a disagreement, a third researcher reviewed the case to achieve the diagnoses (Arajärvi et al., 2004).

Here, we utilized the neuropsychological measurements attained from both schizophrenia patients and their unaffected family members. For some participated families, this test battery had been applied alongside a collection of mRNA and DNA, and performed at two timepoints. The first neuropsychological measurements were performed between the years 1998 and 2002 (first time-point), and the second neuropsychological measurements were performed between the years 2006 and 2008 (second time-point). The first time-point data consisted of 844 individuals from 274 families, and the second time-point 52 individuals from 15 families. Of these, 21 individuals had participated in both data collections (an average of 5 years between measurements). A total of 31 individuals from 10 families participated only in the second time-point collection (Fig. S1 and Table S1).

Genome wide gene-expression data was produced from the mRNA samples collected from the second time-point participants. This second time-point collection had been based upon our prior genetic observations in those families. These include genetic association evidence at the DISC1 (Hennah et al., 2003), NDE1 (Hennah et al., 2007), TOP3B (Stoll et al., 2013) and RELN (Wedenoja et al., 2008) loci that have been reported previously. Of these variants, the DISC1, NDE1 (Bradshaw et al., 2017), and TOP3B (Stoll et al., 2013) loci have previously been studied for altering gene-expression in this cohort. However, DISC1 did not significantly affect gene-expression (Bradshaw et al., 2017), the $T O P 3 B$ deletion only significantly affects the expression level of the TOP3B gene (Stoll et al., 2013), whereas the NDE1 variants are reported to significantly alter the expression levels of a large number of genes, due to the presence of the micro RNA miR-484 being encoded at the NDE1 locus (Bradshaw et al., 2017). Thus, the NDE1 variant rs2242549 was used as a covariate in this study. A medical condition, diagnosed by a clinical expert, that was affecting cognition (head injury, $N=1$ and dementia, $\mathrm{N}=1$ ) or missing all neuropsychological test scores $(N=12)$, were exclusion criteria for the gene expression analyses. In total, neuropsychological measurements, genetic, and gene-expression data was available from 47 individuals ( 15 families) (Table S1). Of the gene-expression study participants (second time-point), $76.6 \%$ originated from the Finnish sub-isolate and 23.4\% from the rest of Finland.

The study has been approved by the Coordinating Ethics committee of the Hospital District of Helsinki and Uusimaa, and informed consent was obtained from all participants. 


\subsection{Phenotypes}

The participants of this study underwent a large neuropsychological assessment including a series of well-validated, and internationally used instruments to measure cognitive ability. For details of the neuropsychological data collection see Tuulio-Henriksson et al., (2002). From the test battery, a total of 14 quantitative neuropsychological measures were chosen for this study, based on the following criteria: 1 . The resulting variable was quantitative, 2. The variable was not missing $>20 \%$ of its' data, and 3. Previous evidence of potential use as a neuropsychological endophenotype was available. From the first time-point $(N=865)$, neuropsychological data together with genetic data has been previously reported (Cannon et al., 2005; Hennah et al., 2005; Paunio et al., 2004; Tuulio-Henriksson et al., 2002; TuulioHenriksson et al., 2003; Wedenoja et al., 2008; Wedenoja et al., 2010), demonstrating that several of our measures meet the criteria for endophenotypes (Gottesman and Gould, 2003), and that these endophenotypes have been useful in decreasing the underlying complexity of the phenotype in genetic studies of familial schizophrenia in Finland. The cognitive endophenotype measures used in the present study were: Immediate recall, Short delay recall, Long delay recall, and Recognition memory from the California Learning Test (CVLT) battery (Delis et al., 1987); Digit Symbol, Block design, Similarities, and Vocabulary from the Wechsler Adult Intelligence Scale-Revised (WAIS-R) battery (Wechsler, 1981); Visual span forward and backward, and Digit span forward and backward Wechsler Memory Scale-Revised (Wechsler, 1987) battery; Stroop interference (Golden, 1978), and Trail Making part A (Reitan, 1985). Trail Making part B was not used because many patients had not managed to complete the task and therefore the finishing time was missing.

Of the 14 variables, three (Recognition memory, Trail making partA, and Stroop interference) did not follow a normal distribution. These three variables were transformed using Blom's normal score ranking formula with IBM SPSS Statistics version 22.0.0.1 Only these normalised values were used for further analysis.

Missing cognitive measures in this study were imputed because: 1 ) constructing factors required full variable information, and 2) to prevent reducing the second time-point sample size of the endophenotype analyses by a minimum of two (4\%: WMS-R Digit span forward and WMS-R Visual span backward) to a maximum of nine (19\%: Stroop interference) study participants. For imputations both first and second time-point measurements were combined $(N=917)$, in order to increase the amount of information available from which the imputations can be made, and thus make them more precise. Of these individuals, $356(38.8 \%)$ were diagnosed with schizophrenia spectrum disorder, 477 were males $(52 \%)$ and the mean age was 49.68 years (range from 22.7 to 88.4 years). Before imputations the test scores of all variables were transformed to the same order of magnitude. Here they were divided either by 10 (Visual span forward, Visual span backward, Digit span forward, Digit span backward, Long delay and Short delay) or by 100 (Immediate recall, Stroop interference, Trail making part A, Digit symbol, Block design, Similarities, and Vocabulary) so that they all were at the same scale as the Recognition memory test scores (The mean of recognition memory test $=0.90$ ). Imputations were performed with IBM SPSS Statistics version 22.0.0.1 using multiple imputation method (MCMC). Time-point, gender, diagnostic status within the broad schizophrenia spectrum of disorders (American Psychiatric Association, 1994), age at measurement and family were used as predictors for imputations. For each variable, the mean value from 10 imputations with 10,000 iterations was calculated and used for further analyses. After imputation, the scores were transformed back to their original scales.

The cognitive measures were hypothesised to group together based on existing theory of the measured cognitive domains, so that the measures from the same cognitive domain were grouped together (expected to correlate with each other). We conducted a confirmatory factor analysis to examine the fit of this hypothesised latent factor structure using the 14 normally distributed cognitive endophenotypes from the first time-point data $(N=865)$, that was not containing any duplicate measurements from the same individual. After grouping, a five-factor, and an alternative three-factor, model was explored (Table S2). For this analysis, gender, diagnostic status of schizophrenia spectrum disorder and age at measurement were used as covariates, and family affects as a random factor. As the cognitive endophenotype measurements of this study had very different metrics, they all were zero centered and transformed to be on the same scale. These Standardised residuals from general linear regression model were used for the factor analysis, and IBM SPSS Statistics version 22.0.0.1 was used for creating the adjusted variables. Factor analysis was conducted with the graphical interface $\Omega$ nyx (version 1.0-937) for creating and estimating structural equation models (SEM) utilizing maximum likelihood estimation procedures (von Oertzen et al., 2015).

In addition to cognitive measures, medication use was explored as a variable which could potentially effect gene-expression levels. Medication data used in this study has been obtained from self-reported data that was collected at the second-time point assessment at the same time as the RNA sample was drawn. Previous studies have shown high concordance between self-reported and official prescription database or pharmacy records for antipsychotic (Haukka et al., 2007), cardiovascular and hypertensive (Drieling et al., 2016) drug use. However, this data means we know neither the dose being taken, nor whether the medication is actually being taken. Here, all but two affected individuals self-reported as taking antipsychotic medication in general. This meant we were not able to fully differentiate any effect of antipsychotic medications on gene expression from disorder status, which was already being used as a covariate. Thus, we broke down the antipsychotic medication group into typical, atypical (excluding clozapine) and clozapine, in order to see if there is any residual effect of these more specific groupings. In addition, we used medication groupings for antidepressant, anticholinergic, benzodiazepines and sedative-hypnotics, mood stabilizers (excluding lithium), lithium, statin, diabetes medication, and antihypertensives and medication for ischemic heart disease (for chemicals included in each group see Table S4).

\subsection{Genotyping}

The procedure used to genotype the NDE1 rs2242549 SNP has been reported in our previous studies (Hennah et al., 2007; Tomppo et al., 2009). Briefly, DNA was extracted from blood samples and genotyping of the NDE1 rs2242549 SNP was performed using the Sequenom platform (Sequenom Inc., San Diego, CA, US) according to the manufacturer's recommendations (Jurinke et al., 2001). The minor allele frequency (MAF) of the NDE1 rs2242549 SNP (specifically the C allele) that was added as a covariate into our analyses was $43.33 \%$ in the 1 st time-point and $43.62 \%$ in the 2nd time-point data (1000 Genomes: All populations $\mathrm{MAF}=46.79 \%$; Finnish from Finland MAF $=49.49 \%$ ).

\subsection{Gene expression profiling}

RNA was extracted from whole blood samples collected into PAXgene tubes. The samples with RNA Integrity Number (RIN) $>8$ were used for further analyses. Genome-wide gene expression measures were assayed using Illumina HumanHT-12 v4.0 Expression BeadChip (Illumina Inc., San Diego, California, USA). Of the 48,212 probes on the chip, 11,976 were significantly detectable at a threshold of $p \leq .01$ in $>90 \%$ of individuals. The expression data for these probes were processed using quantile normalization followed by $\log _{2}$ transformation. Raw anonymous data regarding this family cohort can be accessed at the Gene Expression Omnibus (GEO) database (GSE48072). 


\subsection{Statistical analyses}

Association between genome-wide expression levels and cognitive endophenotypes, in the second time-point data $(N=47)$, was calculated using linear regression model of standardised measures, and included gender, age at measurement, affection status, family, and NDE1 rs2242549 genotype as covariates for the gene-expression values. We applied the false discovery rate (FDR) of $\mathrm{q} \leq 0.05$ to our discovery observations (Storey, 2003). No multiple test correction has been made to account for the 14 endophenotypes and five factors tested. Such a correction would be overly conservative given that these endophenotypes and factors are directly related. Thus, to further lower the risk of type I error of a finding, we report if there is any supportive evidence for that probe in analysis of related endophenotypes. The analysis was performed with R (RStudio version 1.0.136) using qvalue package (Storey, 2003). The post hoc power of our sample to detect gene expression changes was estimated using ssize.fdr (Liu and Hwang, 2007). While this was verified to be sufficient (Fig. S2), this power is expected to be reduced when using multivariate analysis with three covariates as performed here.

Effect of medication on gene-expression measures was explored by fitting a linear regression model for each medication group and each probe using $\mathrm{R}$ (RStudio version 1.0.136).

The findings from microarray analysis were further studied to evaluate any enrichment within specific biological functions of the genes that were associated with the cognitive measures. The analysis was performed with Qiagen's Ingenuity Pathway Analysis software (IPA) (www.ingenuity.com/index.html). To allow more probes to move forward to enrichment analysis, we used a more permissive FDR q-value $\leq 0.10$.

\section{Results}

Descriptive statistics of the cognitive measures used in this study are shown in Table 1 . The 15 families in which the participants belonged included from 1 to 9 individuals each, of which from 1 to 3 were diagnosed with a disorder on the schizophrenia spectrum. In total, $38.3 \%$ of the second time-point individuals were diagnosed with schizophrenia. At the second time-point (when the RNA-sample and the endophenotype measurements were taken), the mean age of the participants was 55 years (range from 40.07 to 84.71 ).

\subsection{Factor analysis}

The hypothesised five-factor model, in which the same cognitive domains and test batteries were grouped together, explored with confirmatory factor analysis (CFA) provided an excellent fit for all 14 cognitive measures. The goodness-of-fit statistics for the best model were: Root Mean Square Error of Approximation (RMSEA) 0.049 (90\% CI 0.048 to 0.063 ) (RMSEA $<0.05$ model of good fit), Comparative Fit Index (CFI) 0.970 (CFI cut-off $>0.95$ ), Trucker Lewis Index (TLI) 0.954 (TLI cut-off $>0.95)$, and $x^{2}(66)=241.16(p<.0001)$. Covariation between the factors ranged from 0.46 to 0.74 . In the five-factor model, Block design was the only variable that was not showing $>0.40$ loading to factors, that is considered as a cut-off for loading. Though, the five-factor model in which this cross-loading on latent factor verbal skills was removed, showed lower model fitting statistics $\left(\right.$ RMSEA $=0.046 ;$ CFI $=0.97 ; \quad$ TLI $\left.=0.945 ; x^{2}(66)=213.44\right)$. Here Block design loaded to factors representing both Processing speed and Verbal skills, which may arise from the fact that Block design usually correlates with a broad range of cognitive tasks including processing speed and verbal intelligence (Cockcroft et al., 2015). In general, Block design loads onto the factor representing either visual ability or reasoning (Nuechterlein et al., 2004). As Block design was the only measure in our test battery that would contribute to generation of a visual ability and/or reasoning factor, such a factor was not generated here. The five-factor model with variables that are loading on each of them are shown in Fig. 1. An alternative three-factor model had lower goodness-of-fit statistics RMSEA $=0.061 ; \quad \mathrm{CFI}=0.95 ; \mathrm{TLI}=0.918$; $\mathrm{x}^{2}(66)=354.42$ ) (Table S2), further suggesting our five-factor model is the best fit.

The factor scores, that were used for further analyses with gene expression data, were calculated for each factor by multiplying each response by the respective regression weight obtained from CFA and the products were summed, for example the factor Verbal learning and memory $=($ Long delay recall * 0.92$)+($ Short delay recall * $0.9)+($ Immediate recall $* 0.87)+($ Recognition memory $* 0.67)$.

\section{Table 1}

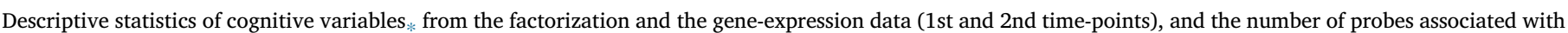

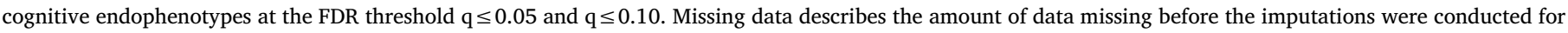

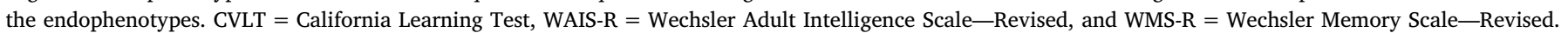

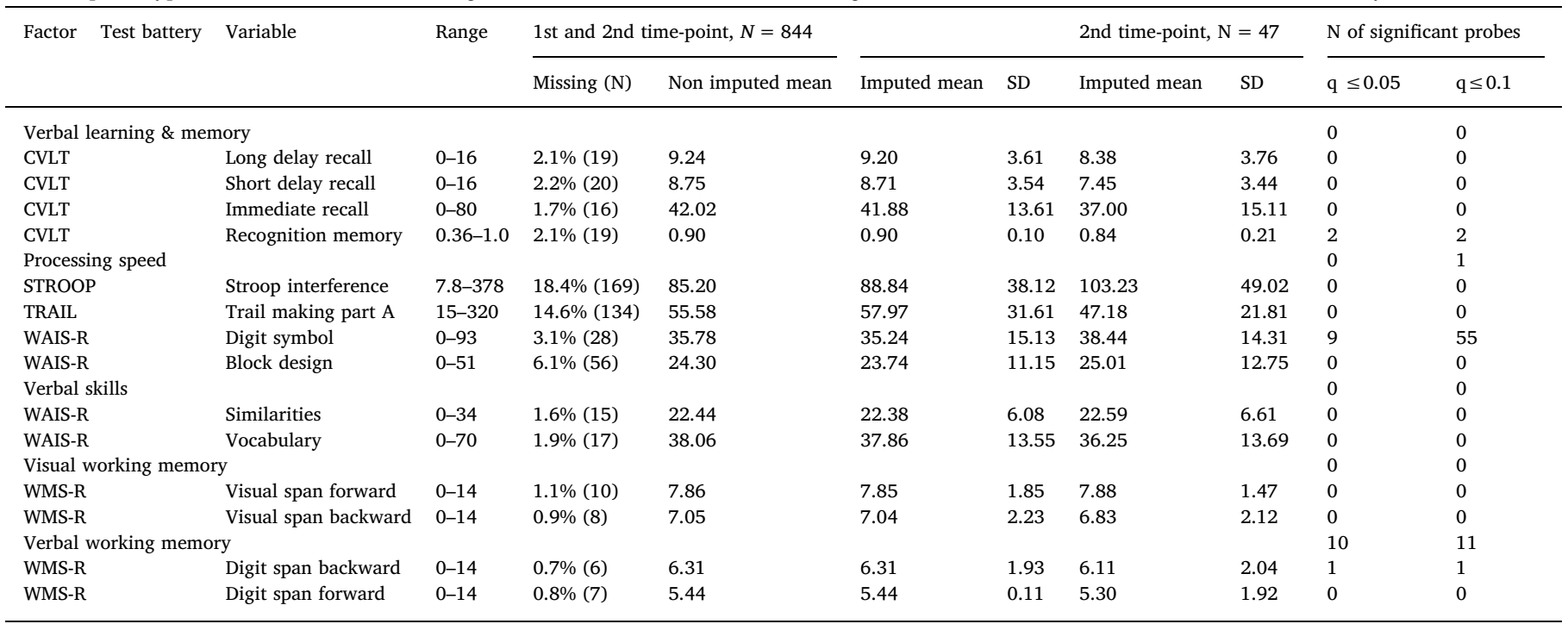

\footnotetext{
* Values shown are based on the raw scores of the variables. Scores have been both normalised and standardised for analysis.
} 


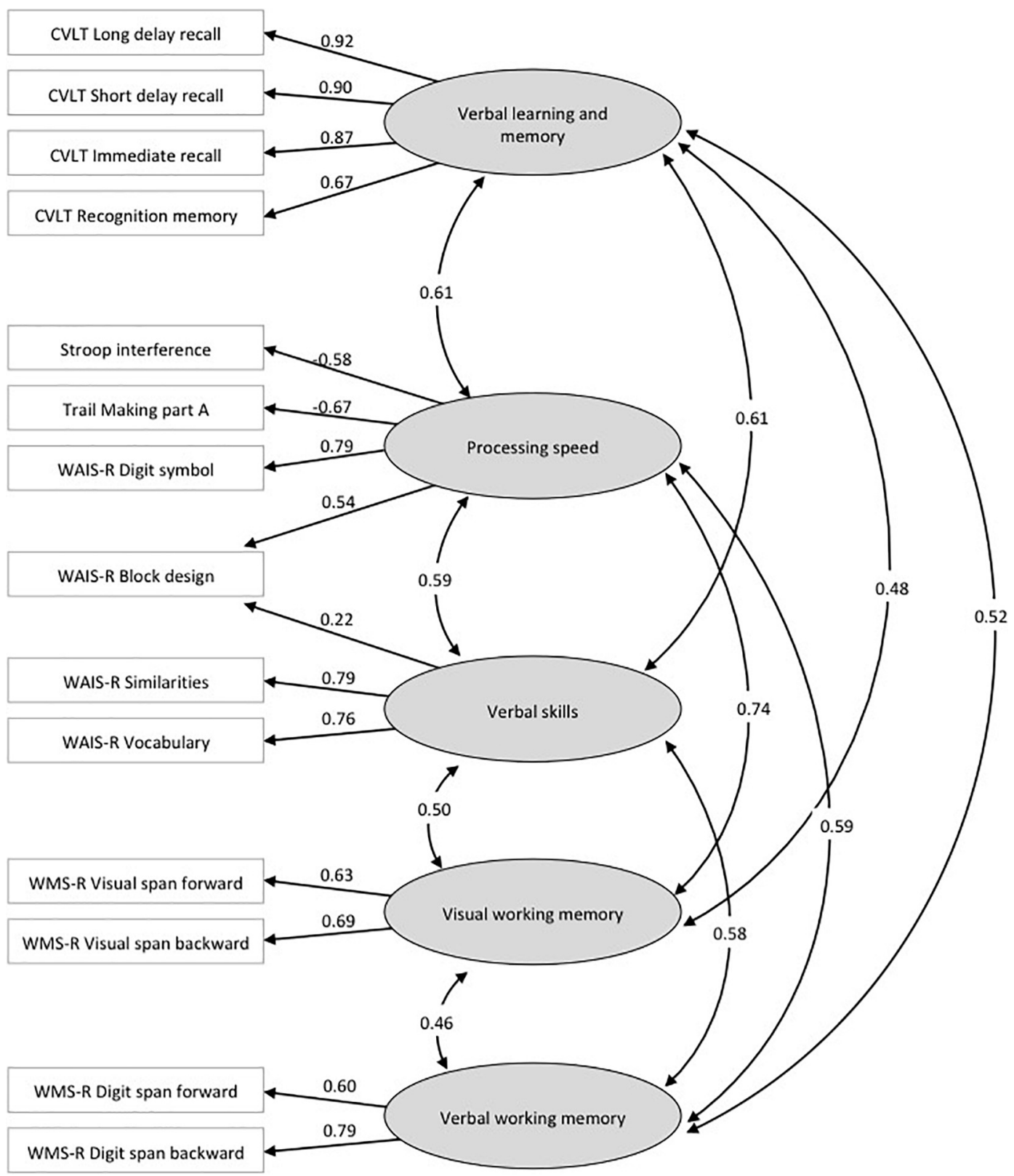

Fig. 1. Five-factor model was obtained from confirmatory factor analysis (factors with grey color).

\subsection{Genome-wide gene expression and cognitive performance}

Of the 11,976 studied probes, expression levels of 10 probes were associated at the FDR $\mathrm{q}<0.05$ level with the factor representing Verbal working memory, and an additional 1 probe at the FDR $q<0.1$ level. One probe was related to the factor Processing speed at the FDR $\mathrm{q}<0.1$ level. Of the cognitive measures from which the factors were constructed, 9 probes were associated at the FDR q $<0.05$ level with WAIS-R Digit symbol (46 probes additionally associated at the FDR $\mathrm{q}<0.1$ level), 2 probes with CVLT Recognition memory, and 1 with WMS-R Digit Span backward. The probe for RTN4 gene was associated with both the factor Processing speed and its' sub-measure WAIS-R Digit symbol ( $\mathrm{q}<0.1$ ). While, the probe for FAM89A was related to both factor Verbal working memory and its' measure WMS-R Digit Span backward $(\mathrm{q}<0.1$ ). The strongest association in our study was provided by the probe for the HYDIN gene with recognition memory $(q=0.016)$. The number of probes exceeding significance level $\mathrm{q}<0.05$, and suggestive significance level $\mathrm{q}<0.1$ are shown in Table 1 and in more detail in Supplementary Table S3 and Fig. S3.

\subsection{Biological pathways in which detected genes were enriched}

Identification of the top canonical pathways and biological functions were performed with Ingenuity Pathway Analysis (IPA) for the factor Verbal working memory, and the specific measure WAIS-R Digit symbol (Table 2) containing 11 and 55 probes, respectively. Pathway analysis showed that the genes associated with cognitive endophenotypes are enriched for functions in immune or inflammatory mechanisms, including EIF2 signalling, and Antigen presentation, as well as in molecular and cellular functions related to cell death and survival, including DNA double-strand break repair by homologous recombination, and DNA double-strand break repair by non-homologous end joining.

\subsection{Medication effect}

A total of 38 different medications belonging to 11 medication groups (splitting antipsychotics into typical, atypical excluding clozapine, and clozapine) were explored (Supplementary Table S5). None of 
Table 2

Biological pathways in which genes associated with cognitive endophenotypes were enriched.

\begin{tabular}{|c|c|c|c|}
\hline Associated endophenotype & Canonical pathway & Overlap molecules & $\mathrm{p}$ \\
\hline \multirow[t]{5}{*}{ WAIS-R Digit symbol } & EIF2 signalling & EIF5, RPL9, RPL14, RPS27 & $6.8 \times 10^{-5}$ \\
\hline & Antigen presentation pathway & HLA-G, PSMB8 & $7.2 \times 10^{-4}$ \\
\hline & Neuroprotective role of THOP1 in Alzheimer's disease & HLA-G, PRKAR2A & $8.4 \times 10^{-4}$ \\
\hline & Molecular mechanisms of cancer & CDKN1B, DAXX, PRKAR2A & $6.9 \times 10^{-3}$ \\
\hline & Breast cancer regulation by stathmin 1 & CDKN1B, PRKAR2A & $2.0 \times 10^{-2}$ \\
\hline \multirow[t]{5}{*}{ Factor Verbal working memory } & Acyl carrier protein metabolism & AASDHPPT & $4.8 \times 10^{-4}$ \\
\hline & Lysine degradation II & AASDHPPT & $2.4 \times 10^{-3}$ \\
\hline & Lysine degradation $\mathrm{V}$ & AASDHPPT & $2.4 \times 10^{-4}$ \\
\hline & DNA double-strand break repair by homologous recombination & RAD50 & $6.8 \times 10^{-3}$ \\
\hline & DNA double-strand break repair by non-homologous end joining & RAD50 & $6.8 \times 10^{-4}$ \\
\hline
\end{tabular}

the probes studied with respect to the medication groups survived false discovery rate correction. However, IPA analysis of 66 probes associated with clozapine use at an uncorrected significance level of $p<.01$ demonstrated that they point towards similar immune related biological pathways to those observed here with cognitive endophenotypes. Canonical pathways enriched for clozapine use are shown in Table S6.

\section{Discussion}

To date, the underlying deficits of human cognitive dysfunction are unknown. In this study we found that gene expression measures can be associated with cognitive endophenotypes for schizophrenia, and thus highlight the biological processes that may be disrupted in these traits. Here, expression levels of 55 RNA probes varied with the WAIS-R Digit symbol, and11 RNA probes with the factor Verbal working memory.

One of the probes associated with the WAIS-R Digit symbol was for the RTN4 gene (Reticulon 4; also known as NOGO) ( $\mathrm{q}=0.03$ ) encoding Nogo protein (isoforms Nogo A, B, and C). In addition to this, RTN4 was associated with the factor Processing speed $(\mathrm{q}<0.1)$ in which the aforementioned sub-measure belonged in, and tentatively (at the level of uncorrected $p<.05$ ) with the three other sub-measures of this factor (Stroop interference, Trail making part A, and WAIS-R Block design). Here, lower cognitive performance correlated with lower RTN4 expression levels. Previously Nogo has been shown to have roles in several developmental and adult synaptic plasticity related processes in the brain, including cell migration, axon guidance, and myelination (Schmandke et al., 2014), and functions including memory and motor learning (Smedfors et al., 2018). In relation to the latter process, Nogo has been demonstrated to be involved in autoimmune-mediated demyelination, a failure of the axons to regenerate after neurodegenerative disorders or injury (Karnezis et al., 2004). Myelin dysfunction has been suggested to be involved in pathogenesis of schizophrenia (Hakak et al., 2001), and a previous study has shown decreased serum expression levels of Nogo in schizophrenia patients (Demirel et al., 2017). In addition to schizophrenia, disturbed Nogo-signalling has been associated with other psychiatric and neurological diseases, and activity of the related genes has been shown to change from birth to old age (Smedfors et al., 2018). Within the probes associated with the factor Verbal working memory, one was representing the PTGER4 gene (prostagladin E receptor 4$)(\mathrm{q}=0.04)$. In addition, PTGER4 was tentatively associated (at the level of uncorrected $p<.001$ ) with all submeasures of the factor (WMS-R Digit span backward, and WMS-R Digit span forward). Here, lower cognitive performance correlated with higher PTGER4 expression levels. Contrary to our observations, a previous study noted that the expression levels of immune-modulatory genes, including PTGER4, were downregulated in the brains of schizophrenia patients when compared to controls (Schmitt et al., 2011). Lastly, a probe representing the hydrocephalus inducing gene HYDIN was associated with the sub-measure assessing recognition memory performance $(\mathrm{q}=0.02)$. In addition to this measure, this probe was tentatively associated (at the level of uncorrected $p<.0005$ ) for other sub-measures of the factor Verbal learning and memory (Immediate, Short delay, and Long delay recall) and the factor itself (comprising of measures Recognition memory, Immediate, Short delay, and Long delay recall). Lower cognitive performance was related to lower HYDIN expression levels. In previous studies, deletions and duplications of the HYDIN gene location has been associated with abnormal head size (microcephaly or macrocephaly), and can manifest with developmental, congenital, and behavioural abnormalities (Brunetti-Pierri et al., 2008).

When the genes varying with cognitive performance were explored together, enrichment within immune processes, and protein synthesis control was detected (Table 2). Similarly, a previous study exploring cognitive performance and gene expression levels showed enrichment of genes related to immunology, RNA processing, and DNA replication (Zheutlin et al., 2016). Specifically, they identified six genes related to T and B cell signalling pathways (Zheutlin et al., 2016), which have important roles also in the antigen presentation pathway. This previous study used the CVLT performance as an endophenotype, while in our study the observations of changes in expression level of genes related to the antigen presentation pathway were correlated with the Digit symbol test, and not those measures used here from the CVLT. Furthermore, immune pathways, including antigen processing and presentation, genes (MCH-region, e.g. HLA-G gene) showed enrichment in a study of schizophrenia patients with cognitive impairment (Wu et al., 2016). Thus there is a growing body of evidence suggesting that the aetiology of schizophrenia may involve infectious or autoimmune processes from epidemiological (Feigenson et al., 2014), genome-wide loci (Schizophrenia Working Group of the Psychiatric Genomics, 2014), genetic and proteomic (Chan et al., 2017), and gene expression (Gardiner et al., 2013; Schmitt et al., 2011; Wu et al., 2016; Xu et al., 2012) approaches.

Several cognitive endophenotypes, including general intelligence, information processing speed, and memory, has been used to study cognitive performance in schizophrenia (Hubbard et al., 2016), and in healthy individuals (Ibrahim-Verbaas et al., 2016; Luciano et al., 2011; Sniekers et al., 2017). The genetic background between cognitive functioning and psychiatric diseases has been demonstrated to be shared. A recent meta-analysis of genome-wide studies for intelligence implicated association of 22 genes with intelligence, of which seven have previously been shown to be associated to schizophrenia (CYP2D6, NAGA, NDUFA6, TCF20, SEPT3, FAM109B and MEF2C) (Sniekers et al., 2017). Furthermore, a schizophrenia polygenetic risk score was associated with lower performance intelligence, and in the reciprocal analysis a polygenetic risk score for performance intelligence associated with increased risk for schizophrenia, although the genetic overlap with full intelligence was weaker (Hubbard et al., 2016).

Epidemiological studies suggest that familial history of schizophrenia is the strongest single indicator of individual schizophrenia risk (Mortensen et al., 2010). There is consistent evidence of correlation between family history of schizophrenia and a slight reduction in a 
persons' general cognitive ability (McGrath et al., 2014; Mortensen et al., 1999; Mortensen et al., 2010; Tuulio-Henriksson et al., 2003). Overall, information processing speed is an important cognitive process that is impaired in major psychiatric illness (Dickinson, 2008) and at old age. In our study, WAIS-R Digit symbol test was measuring information processing speed. Previous studies have shown that genes associated with information processing speed are related to the biological functions; cell junction, focal adhesion, receptor binding, and cellular metabolic process (Luciano et al., 2011). While another study reported association between information processing speed and the CADM2 gene, which encodes a protein involved in glutamate signalling and is a candidate gene for Autism Spectrum Disorder, and personality (Ibrahim-Verbaas et al., 2016).

Previous studies have shown gene expression changes related to lithium treatment monotherapy in patients with bipolar disorder (Anand et al., 2016) and for clozapine treatment monotherapy in patients with psychosis (Harrison et al., 2016). We explored 50 medications that belonged to 11 medication groups (typical antipsychotic, atypical antipsychotic (excluding clozapine), clozapine, antidepressive, anticholinergic, benzodiazepines, lithium, mood stabilizers, statin, cardiovascular, and hypertensive) for possible effects on whole blood gene expression levels. However, several individuals in our data were on polypharmacy and had been taking the medications for years, it was not possible to measure the effect of monotherapy in our data. In this cohort, no medication group tested had a significant effect on gene expression measures, and was therefore not included as a covariate in our analyses conducted with the cognitive endophenotypes. However, here diagnosis almost completely overlaps with antipsychotic medication reporting, and we needed to account for the effect of diagnosis on both endophenotypes and gene expression by including it as a covariate. Thus we were unable to test the effect of antipsychotic medications in general, as their effect is likely entwined in this cohort with that of diagnosis. We analysed the probes that showed tentative uncorrected association (at the level of $p<.01$ ) with clozapine use, and noticed that different genes were associated with clozapine use than with our cognitive endophenotypes. Intriguingly, the canonical pathways in which the probes related to clozapine were enriched are related to biological functions linked to peripheral immune cell disruption, including abnormal morphology, lack of, and differentiation of lymphocytes. Clozapine use is known to have effects on peripheral immune cells, and cause severe conditions including neutropenia, which is why regular blood monitoring is required during treatment (Howes et al., 2012).

The main limitation of the study is the small sample size and the implied reduced power to detect changes in gene expression comes with it. However, we have demonstrated that we have $80 \%$ power to detect large changes in gene expression (here maximum effect size $\Delta=0.80$ ), which is for the observed 90th percentile of the standard deviation for all genes from our data (SD $\sigma=1.34$ ) (Fig. S2). This power is reduced in multivariate analysis with covariates. However, the sample used in this study is relatively homogenous, as the study cohort is Finnish data with individuals diagnosed with disorders along the schizophrenia spectrum and their family members. With a less homogenous sample the gene expression standard deviations would be larger and thus the changes in probe expression levels would not be detectable with the same sample size. Another limitation is validation of the results. This study was designed to explore if whole blood gene expression changes could be associated with cognitive performance, not to accurately determine the fold-changes of these findings. Thus, we did not validate our microarray results with RT-qPCR. Instead several other methods were applied to keep the number of false positives low. As the smaller reported $p$-value has shown to elevate the confidence in the accuracy of the microarray results (Chuaqui et al., 2002), a stringent FDR of 5\% was applied for our analyses. We report all findings at this level, however, these would not survive multiple test correction across the 19 tests performed (Bonferroni Threshold $\mathrm{q}<0.0026$ ). Thus, we have focused on those probes with supporting evidence from the analysis of these related endophenotypes. Furthermore, the biological relevance of the pathways in which the detected genes were enriched further support our results (for enrichment analyses FDR 10\% was used). A separate healthy control group was not used in this study because the sample included healthy family members.

Our observation that expression of immunological process related genes vary with cognitive performance in familial schizophrenia further supports the genomic discoveries made (Chan et al., 2017; Gardiner et al., 2013; Schizophrenia Working Group of the Psychiatric Genomics, 2014; Schmitt et al., 2011; Wu et al., 2016; Xu et al., 2012), suggesting that inflammatory responses are related to the pathophysiology and development of schizophrenia. Thus immune or inflammatory processes may be of biological interest for future drug design towards schizophrenia and the cognitive dysfunctions that underlie it.

\section{Acknowledgements}

This work was supported by the Academy of Finland (grant numbers: 128504, 259589, 265097), EU-FP7 (MC-ITN number 607616 "INSENS"), and Orion Farmos Research Foundation. Gene-expression and genotyping laboratory analysis was performed by the Institute for Molecular Medicine Finland FIMM Technology Centre, University of Helsinki.

\section{Role of funding source}

Funding for this study was provided by the Academy of Finland (grant numbers: 128504, 259589, 265097), EU-FP7 (MC-ITN number 607616 "IN-SENS"), and Orion Farmos Research Foundation. The funders had no further role in study design; in the collection, analysis and interpretation of data; in the writing of the report; and in the decision to submit the paper for publication.

\section{Contributors}

LUV, MTH, and WH wrote the manuscript text; LUV and WH prepared the manuscript tables and figures; WH designed the study; TP, JS, and JL provided access to samples and data; LUV, AOA, and VS performed the analysis. All authors have reviewed the manuscript and approved the final version to be published.

\section{Conflict of interest}

All authors declare that they have no conflicts of interest.

\section{Ethical statement}

In all studies, the principles recommended in the Declaration of Helsinki and its amendments were followed. The study has been approved by the Coordinating Ethics committee of the Hospital District of Helsinki and Uusimaa. Informed consent was obtained from all participants.

\section{Appendix A. Supplementary data}

Supplementary data to this article can be found online at https:// doi.org/10.1016/j.pnpbp.2018.07.003.

\section{References}

American Psychiatric Association, 1994. Diagnostic and Statistical Manual of Mental Disorders, 4th edn. American Psychiatric Press, Washington, DC.

Anand, A., McClintick, J.N., Murrell, J., Karne, H., Nurnberger, J.I., Edenberg, H.J., 2016. Effects of Lithium monotherapy for bipolar disorder on gene expression in peripheral lymphocytes. Mol Neuropsychiatry 2 (3), 115-123.

Arajärvi, R., Haukka, J., Varilo, T., Suokas, J., Juvonen, H., Suvisaari, J., Muhonen, M., 
Suominen, K., Tuulio-Henriksson, A., Schreck, M., Hovatta, I., Partonen, T., Lönnqvist, J., 2004. Clinical phenotype of schizophrenia in a Finnish isolate. Schizophr. Res. 67, 195-205.

Bradshaw, N.J., Ukkola-Vuoti, L.M.P., Zheutlin, A.B., Ortega-Alonso, A., TorniainenHolm, M., Sinha, V., Therman, S., Paunio, T., Suvisaari, J., Lonnqvist, J., Cannon, T.D., Haukka, J., Hennah, W., 2017. The NDE1 genomic locus can affect treatment of psychiatric illness through gene expression changes related to MicroRNA-484. Open Biology 7, 170153.

Braff, D.L., 2015. The importance of endophenotypes in schizophrenia research. Schizophr. Res. 163, 1-8.

Brunetti-Pierri, N., Berg, J.S., Scaglia, F., Belmont, J., Bacino, C.A., Sahoo, T., Lalani, S.R., Graham, B., Lee, B., Shinawi, M., Shen, J., Kang, S.H., Pursley, A., Lotze, T., Kennedy, G., Lansky-Shafer, S., Weaver, C., Roeder, E.R., Grebe, T.A., Arnold, G.L., Hutchison, T., Reimschisel, T., Amato, S., Geragthy, M.T., Innis, J.W., Obersztyn, E., Nowakowska, B., Rosengren, S.S., Bader, P.I., Grange, D.K., Naqvi, S., Garnica, A.D., Bernes, S.M., Fong, C.T., Summers, A., Walters, W.D., Lupski, J.R., Stankiewicz, P. Cheung, S.W., Patel, A., 2008. Recurrent reciprocal 1q21.1 deletions and duplications associated with microcephaly or macrocephaly and developmental and behavioral abnormalities. Nat Genet. 40 (12), 1466-1471.

Cannon, T.D., Hennah, W., van Erp, T.G., Thompson, P.M., Lonnqvist, J., Huttunen, M., Gasperoni, T., Tuulio-Henriksson, A., Pirkola, T., Toga, A.W., Kaprio, J., Mazziotta, J., Peltonen, L., 2005. Association of DISC1/TRAX haplotypes with schizophrenia, reduced prefrontal gray matter, and impaired short- and long-term memory. Arch. Gen. Psychiatry 62, 1205-1213.

Chan, M.K., Cooper, J.D., Heilmann-Heimbach, S., Frank, J., Witt, S.H., Nöthen, M.M., Steiner, J., Rietschel, M., Bahn, S., 2017. Associations between SNPs and immunerelated circulating proteins in schizophrenia. Sci Rep. 7 (1), 12586.

Chuaqui, R.F., Bonner, R.F., Best, C.J., Gillespie, J.W., Flaig, M.J., Hewitt, S.M., Phillips, J.L., Krizman, D.B., Tangrea, M.A., Ahram, M., Linehan, W.M., Knezevic, V., EmmertBuck, M.R., 2002. Post-analysis follow-up and validation of microarray experiments. Nat Genet. 32 (Suppl), 509-514 Dec.

Cockcroft, K., Alloway, T., Copello, E., Milligan, R., 2015. A cross-cultural comparison between south African and British students on the Wechsler adult intelligence scales third edition (WAIS-III). Front. Psychol. 6, 297.

Cornblatt, B.A., Erlenmeyer-Kimling, L., 1985. Global attentional deviance as a marker of risk for schizophrenia: specificity and predictive validity. J. Abnorm. Psychol. 94, 470-486.

Delis, D.K., Kaplan, E., Ober, B.A., 1987. California verbal learning test. In: Manual, Research Edition. The Psychological Corporation, Harcourt Brace \& Company, San Antonio, TX.

Demirel, Ö.F., Cetin, İ., Turan, S., Sağlam, T., Yıldız, N., Duran, A., 2017. Decreased expression of $\alpha$-Synuclein, Nogo-a and UCH-L1 in patients with schizophrenia: a preliminary serum study. Psychiatry Investig 14 (3), 344-349.

Dickinson, D., 2008. Digit symbol coding and general cognitive ability in schizophrenia: worth another look? Br. J. Psychiatry 193 (5), 354-356.

Dickinson D., Iannone V.N., Wilk C.M., Gold J.M, 2004. General and specific cognitive deficits in schizophrenia. Biol. Psychiatry 55:826-833.

Drieling, R.L., Lacroix, A.Z., Beresford, S.A., Boudreau, D.M., Kooperberg, C., Heckbert, S.R., 2016. Validity of self-reported medication use compared with pharmacy Records in a Cohort of older women: findings from the Women's Health Initiative. Am. J. Epidemiol. 184, 233-238.

Feigenson, K.A., Kusnecov, A.W., Silverstein, S.M., 2014. Inflammation and the two-hit hypothesis of schizophrenia. Neurosci. Biobehav. Rev. 38, 72-93.

Flint, J., Munafo, M.R., 2007. The endophenotype concept in psychiatric genetics. Psychol. Med. 37, 163-180.

Gardiner, E.J., Cairns, M.J., Liu, B., Beveridge, N.J., Carr, V., Kelly, B., Scott, R.J., Tooney, P.A., 2013. Gene expression analysis reveals schizophrenia-associated dysregulation of immune pathways in peripheral blood mononuclear cells. J. Psychiatr. Res. 47 (4), 425-437.

Golden, C., 1978. Stroop Color and Word Test: Manual for Clinical and Experimenta Uses. Stoelting, Chicago.

Gottesman, I.I., Gould, T.D., 2003. The endophenotype concept in psychiatry: etymology and strategic intentions. Am. J. Psychiatry 160, 636-645.

Gottesman, I.I., Shields, J., 1973. Genetic theorizing and schizophrenia. Br. J. Psychiatry $122,15-30$.

Hakak, Y., Walker, J.R., Li, C., Wong, W.H., Davis, K.L., Buxbaum, J.D., Haroutunian, V., Fienberg, A.A., 2001. Genome-wide expression analysis reveals dysregulation of myelination-related genes in chronic schizophrenia. Proc. Natl. Acad. Sci. U. S. A. 98, $4746-4751$.

Harrison, R.N., Murray, R.M., Lee, S.H., Paya Cano, J., Dempster, D., Curtis, C.J., Dima, D., Gaughran, F., Breen, G., de Jong, S., 2016. Gene-expression analysis of clozapine treatment in whole blood of patients with psychosis. Psychiatr. Genet. 26, 211-217.

Haukka, J., Suvisaari, J., Tuulio-Henriksson, A., Lönnqvist, J., 2007. High concordance between self-reported medication and official prescription database information. Eur. J. Clin. Pharmacol. 63, 1069-1074.

Hennah, W., Varilo, T., Kestila, M., Paunio, T., Arajarvi, R., Haukka, J., Parker, A., Martin, R., Levitzky, S., Partonen, T., Meyer, J., Lonnqvist, J., Peltonen, L., Ekelund, J., 2003. Haplotype transmission analysis provides evidence of association for DISC1 to schizophrenia and suggests sex-dependent effects. Hum. Mol. Genet. 12, 3151-3159.

Hennah, W., Tuulio-Henriksson, A., Paunio, T., Ekelund, J., Varilo, T., Partonen, T., Cannon, T.D., Lonnqvist, J., Peltonen, L., 2005. A haplotype within the DISC1 gene is associated with visual memory functions in families with a high density of schizophrenia. Mol. Psychiatry 10, 1097-1103.

Hennah, W., Tomppo, L., Hiekkalinna, T., Palo, O.M., Kilpinen, H., Ekelund, J., TuulioHenriksson, A., Silander, K., Partonen, T., Paunio, T., Terwilliger, J.D., Lonnqvist, J., Peltonen, L., 2007. Families with the risk allele of DISC1 reveal a link between schizophrenia and another component of the same molecular pathway, NDE1. Hum. Mol. Genet. 16, 453-462.

Hovatta, I., Terwilliger, J.D., Lichtermann, D., Mäkikyrö, T., Suvisaari, J., Peltonen, L., Lönnqvist, J., 1997. Schizophrenia in the genetic isolate of Finland. Am J Med Genet 74 (4), 353-360.

Hovatta, I., Lichtermann, D., Juvonen, H., Suvisaari, J., Terwilliger, J.D., Arajarvi, R. Kokko-Sahin, M.L., Ekelund, J., Lonnqvist, J., Peltonen, L., 1998. Linkage analysis of putative schizophrenia gene candidate regions on chromosomes 3p, 5q, 6p, 8p, 20p and 22q in a population-based sampled Finnish family set. Mol. Psychiatry 3, $452-457$.

Howes, O.D., Vergunst, F., Gee, S., McGuire, P., Kapur, S., Taylor, D., 2012. Adherence to treatment guidelines in clinical practice: study of antipsychotic treatment prior to clozapine initiation. Br. J. Psychiatry 201, 481-485.

Hubbard, L., Tansey, K.E., Rai, D., Jones, P., Ripke, S., Chambert, K.D., Moran, J.L., McCarroll, S.A., Linden, D.E., Owen, M.J., O'Donovan, M.C., Walters, J.T., Zammit, S., 2016. Evidence of common genetic overlap between schizophrenia and cognition. Schizophr. Bull. 42 (3), 832-842.

Ibrahim-Verbaas, C.A., Bressler, J., Debette, S., Schuur, M., Smith, A.V., Bis, J.C., Davies, G., Trompet, S., Smith, J.A., Wolf, C., Chibnik, L.B., Liu, Y., Vitart, V., Kirin, M., Petrovic, K., Polasek, O., Zgaga, L., Fawns-Ritchie, C., Hoffmann, P., Karjalainen, J., Lahti, J., Llewellyn, D.J., Schmidt, C.O., Mather, K.A., Chouraki, V., Sun, Q., Resnick, S.M., Rose, L.M., Oldmeadow, C., Stewart, M., Smith, B.H., Gudnason, V., Yang, Q., Mirza, S.S., Jukema, J.W., Dejager, P.L., Harris, T.B., Liewald, D.C., Amin, N., Coker, L.H., Stegle, O., Lopez, O.L., Schmidt, R., Teumer, A., Ford, I., Karbalai, N., Becker, J.T., Jonsdottir, M.K., Au, R., Fehrmann, R., Herms, S., Nalls, M., Zhao, W., Turner, S.T., Yaffe, K., Lohman, K., van Swieten, J.C., Kardia, S., Knopman, D.S., Meeks, W.M., Heiss, G., Holliday, E.G., Schofield, P.W., Tanaka, T., Stott, D.J., Wang, J., Ridker, P., Gow, A.J., Pattie, A., Starr, J.M., Hocking, L.J., Armstrong, N.J., McLachlan, S., Shulman, J.M., Pilling, L.C., Eiriksdottir, G., Scott, R.J., Kochan, N.A., Palotie, A., Hsieh, Y.C., Eriksson, J.G., Penman, A., Gottesman, R.F., Oostra, B.A., Yu, L., Destefano, A.L., Beiser, A., Garcia, M., Rotter, J.I., Nothen, M.M., Hofman, A., Slagboom, P.E., Westendorp, R., Buckley, B.M., Wolf, P.A., Uitterlinden, A.G., Psaty, B.M., Grabe, H.J., Bandinelli, S., Chasman, D.I., Grodstein, F., Raikkonen, K., Lambert, J.C., Porteous, D.J., Generation, S., Price, J.F., Sachdev, P.S., Ferrucci, L., Attia, J.R., Rudan, I., Hayward, C., Wright, A.F., Wilson, J.F., Cichon, S., Franke, L., Schmidt, H., Ding, J., de Craen, A., Fornage, M., Bennett, D.A., Deary, I.J., Ikram, M.A., Launer, L.J., Fitzpatrick, A.L., Seshadri, S., van Duijn, C.M., Mosley, T.H., 2016. GWAS for executive function and processing speed suggests involvement of the CADM2 gene. Mol. Psychiatry 21, 189-197.

Jurinke, C., van den Boom, D., Cantor, C.R., Koster, H., 2001. Automated genotyping using the DNA MassArray technology. Methods Mol. Biol. 170, 103-116.

Karnezis, T., Mandemakers, W., McQualter, J.L., Zheng, B., Ho, P.P., Jordan, K.A., Murray, B.M., Barres, B., Tessier-Lavigne, M., Bernard, C.C., 2004. The neurite outgrowth inhibitor Nogo a is involved in autoimmune-mediated demyelination. Nature Neurosci. 7, 736-744.

Keefe, R.S., Buchanan, R.W., Marder, S.R., Schooler, N.R., Dugar, A., Zivkov, M., Stewart, M., 2013. Clinical trials of potential cognitive-enhancing drugs in schizophrenia: what have we learned so far? Schizophr. Bull. 39, 417-435.

Koola, M.M., Buchanan, R.W., Pillai, A., Aitchison, K.J., Weinberger, D.R., Aaronson, S.T., Dickerson, F.B., 2014. Potential role of the combination of galantamine and memantine to improve cognition in schizophrenia. Schizophr. Res. 157 (1-3), 84-89.

Liu, P., Hwang, J.T.G., 2007. Quick calculation for sample size while controlling false discovery rate with application to microarray analysis. Bioinformatics 23, 739-746.

Luciano, M., Hansell, N.K., Lahti, J., Davies, G., Medland, S.E., Raikkonen, K., Tenesa, A., Widen, E., McGhee, K.A., Palotie, A., Liewald, D., Porteous, D.J., Starr, J.M. Montgomery, G.W., Martin, N.G., Eriksson, J.G., Wright, M.J., Deary, I.J., 2011. Whole genome association scan for genetic polymorphisms influencing information processing speed. Biol. Psychol. 86, 193-202.

McGrath, J.J., Wray, N.R., Pedersen, C.B., Mortensen, P.B., Greve, A.N., Petersen, L., 2014. The association between family history of mental disorders and general cognitive ability. Transl. Psychiatry 4, e412.

Mortensen, P.B., Pedersen, C.B., Westergaard, T., Wohlfahrt, J., Ewald, H., Mors, O. Andersen, P.K., Melbye, M., 1999. Effects of family history and place and season of birth on the risk of schizophrenia. N. Engl. J. Med. 340, 603-608.

Mortensen, P.B., Pedersen, M.G., Pedersen, C.B., 2010. Psychiatric family history and schizophrenia risk in Denmark: which mental disorders are relevant? Psychol. Med. 40, 201-210.

Nuechterlein, K.H., Barch, D.M., Gold, J.M., Goldberg, T.E., Green, M.F., Heaton, R.K., 2004. Identification of separable cognitive factors in schizophrenia. Schizophr. Res. 72, 29-39.

Paunio, T., Tuulio-Henriksson, A., Hiekkalinna, T., Perola, M., Varilo, T., Partonen, T., Cannon, T.D., Lonnqvist, J., Peltonen, L., 2004. Search for cognitive trait components of schizophrenia reveals a locus for verbal learning and memory on 4q and for visual working memory on 2q. Hum. Mol. Genet. 13, 1693-1702.

Reitan, R.W., 1985. The Halstead Reitan Neuropsychological Test Battery. Neuropsychology Press Tuscon, AZ. Schmitt, A., Leonardi-Essmann, F., Durrenberger, P.F., Parlapani, E., Schneider-Axmann, T., Spanagel, R., Arzberger, T., Kretzschmar, H., Herrera-Marschitz, M., Gruber, O., Reynolds, R., Falkai, P., Gebicke-Haerter, P.J., 2011. Regulation of immune-modulatory genes in left superior temporal cortex of schizophrenia patients: a genome-wide microarray study. World J Biol Psychiatry 12, 201-215.

Schizophrenia Working Group of the Psychiatric Genomics, 2014. Biological insights from 108 schizophrenia-associated genetic loci. Nature 511, 421-427.

Schmandke, A., Schmandke, A., Schwab, M.E., 2014. Nogo-a: multiple roles in CNS development, maintenance, and disease. Neuroscientist 20 (4), 372-386.

Schmitt, A., Leonardi-Essmann, F., Durrenberger, P.F., Parlapani, E., Schneider-Axmann, 
T., Spanagel, R., Arzberger, T., Kretzschmar, H., Herrera-Marschitz, M., Gruber, O. Reynolds, R., Falkai, P., Gebicke-Haerter, P.J., 2011. Regulation of immune-modulatory genes in left superior temporal cortex of schizophrenia patients: a genomewide microarray study. World J Biol Psychiatry 12 (3), 201-215.

Smedfors, G., Olson, L., Karlsson, T.E., 2018. A Nogo-like signaling perspective from birth to adulthood and in old age: brain expression patterns of ligands, receptors and modulators. Front Mol Neurosci. 11, 42.

Smeland, O.B., Frei, O., Kauppi, K., Hill, W.D., Li, W., Wang, Y., Krull, F., Bettella, F., Eriksen, J.A., Witoelar, A., Davies, G., Fan, C.C., Thompson, W.K., Lam, M., Lencz, T., Chen, C.H., Ueland, T., Jonsson, E.G., Djurovic, S., Deary, I.J., Dale, A.M., Andreassen, O.A., Neuro, C.C.W.G., 2017. Identification of genetic loci jointly in fluencing schizophrenia risk and the cognitive traits of verbal-numerical reasoning, reaction time, and general cognitive function. JAMA Psychiatry 74 (10), 1065-1075.

Sniekers, S., Stringer, S., Watanabe, K., Jansen, P.R., Coleman, J.R.I., Krapohl, E., Taskesen, E., Hammerschlag, A.R., Okbay, A., Zabaneh, D., Amin, N., Breen, G., Cesarini, D., Chabris, C.F., Iacono, W.G., Ikram, M.A., Johannesson, M., Koellinger, P., Lee, J.J., Magnusson, P.K.E., McGue, M., Miller, M.B., Ollier, W.E.R., Payton, A., Pendleton, N., Plomin, R., Rietveld, C.A., Tiemeier, H., van Duijn, C.M., Posthuma, D., 2017. Genome-wide association meta-analysis of 78,308 individuals identifies new loci and genes influencing human intelligence. Nat. Genet. 9 (7), 1107-1112.

Stoll, G., Pietilainen, O.P.H., Linder, B., Suvisaari, J., Brosi, C., Hennah, W., Leppa, V., Torniainen, M., Ripatti, S., Ala-Mello, S., Plottner, O., Rehnstrom, K., TuulioHenriksson, A., Varilo, T., Tallila, J., Kristiansson, K., Isohanni, M., Kaprio, J., Eriksson, J.G., Raitakari, O.T., Lehtimaki, T., Jarvelin, M.R., Salomaa, V., Hurles, M., Stefansson, H., Peltonen, L., Sullivan, P.F., Paunio, T., Lonnqvist, J., Daly, M.J., Fischer, U., Freimer, N.B., Palotie, A., 2013. Deletion of TOP3beta, a component of FMRP-containing mRNPs, contributes to neurodevelopmental disorders. Nat. Neurosci. 16, 1228-1237.

Storey, J.D., 2003. The positive false discovery rate: a Bayesian interpretation and the qvalue. Ann. Stat. 31, 2013-2035.

Tomppo, L., Hennah, W., Lahermo, P., Loukola, A., Tuulio-Henriksson, A., Suvisaari, J., Partonen, T., Ekelund, J., Lonnqvist, J., Peltonen, L., 2009. Association between genes of disrupted in schizophrenia 1 (DISC1) interactors and schizophrenia supports the role of the DISC1 pathway in the etiology of major mental illnesses. Biol. Psychiatry 65, 1055-1062.

Tuulio-Henriksson, A., Haukka, J., Partonen, T., Varilo, T., Paunio, T., Ekelund, J., Cannon, T.D., Meyer, J.M., Lonnqvist, J., 2002. Heritability and number of quantitative trait loci of neurocognitive functions in families with schizophrenia. Am. J. Med. Genet. 114, 483-490.

Tuulio-Henriksson, A., Arajarvi, R., Partonen, T., Haukka, J., Varilo, T., Schreck, M., Cannon, T., Lonnqvist, J., 2003. Familial loading associates with impairment in visual span among healthy siblings of schizophrenia patients. Biol. Psychiatry 54, 623-628.

von Oertzen, T., Brandmaier, A.M., Tsang, S., 2015. Structural equation modeling with omega nyx. Struct Equ Modeling 22, 148-161.

Wechsler, D., 1981. Wechsler Adult Intelligence Scale - Revised (WAIS-R). In: Manual. Harcourt Brace Jovanovich [for] Psychological Corp., New York, NY.

Wechsler, D., 1987. Wechsler Memory Scale - Revised (WMS-R), Manual. The Psychological Corporation, San Antonio.

Wedenoja, J., Loukola, A., Tuulio-Henriksson, A., Paunio, T., Ekelund, J., Silander, K. Varilo, T., Heikkila, K., Suvisaari, J., Partonen, T., Lonnqvist, J., Peltonen, L., 2008. Replication of linkage on chromosome 7q22 and association of the regional Reelin gene with working memory in schizophrenia families. Mol. Psychiatry 13, 673-684.

Wedenoja, J., Tuulio-Henriksson, A., Suvisaari, J., Loukola, A., Paunio, T., Partonen, T., Varilo, T., Lonnqvist, J., Peltonen, L., 2010. Replication of association between working memory and Reelin, a potential modifier gene in schizophrenia. Biol. Psychiatry 67, 983-991.

Wu, J.Q., Green, M.J., Gardiner, E.J., Tooney, P.A., Scott, R.J., Carr, V.J., Cairns, M.J., 2016. Altered neural signaling and immune pathways in peripheral blood mononuclear cells of schizophrenia patients with cognitive impairment: a transcriptome analysis. Brain Behav. Immun. 53, 194-206.

Xu, J., Sun, J., Chen, J., Wang, L., Li, A., Helm, M., Dubovsky, S.L., Bacanu, S.A., Zhao, Z., Chen, X., 2012. RNA-Seq analysis implicates dysregulation of the immune system in schizophrenia. BMC Genomics 13 (Suppl 8), S2.

Zheutlin, A.B., Viehman, R.W., Fortgang, R., Borg, J., Smith, D.J., Suvisaari, J., Therman, S., Hultman, C.M., Cannon, T.D., 2016. Cognitive endophenotypes inform genomewide expression profiling in schizophrenia. Neuropsychology 30, 40-52. 